\title{
The Role of Primary Health Care in Hepatitis B Testing and Management: A Case Study
}

\author{
Jacqueline A. Richmond ${ }^{1,2,3} \cdot$ Joe Sasadeusz $^{1} \cdot$ Meredith Temple-Smith $^{4}$
}

Published online: 22 June 2017

(C) The Author(s) 2017. This article is an open access publication

\begin{abstract}
Hepatitis B is a complex disease requiring lifelong management. Infection is linked to birth in high prevalence regions including Africa and Asia. Best practice guidelines identify who to test for hepatitis B, however, a significant proportion of Australians with hepatitis $\mathrm{B}$ have not been diagnosed, and are subsequently at risk of serious morbidity and mortality. This study sought to address the gap between current and optimal hepatitis B testing in a primary care clinic with a likely high population of undiagnosed hepatitis B. Between September 2015 and December 2016, four interventions aimed at enhancing general practitioner testing practices were implemented: staff education, quality improvement and patient-triggered activities. Compared to the baseline (2014) the following parameters all increased in 2016: the number of patients tested (15 tests per month in 2014, 24 tests per months in 2016), the correct ordering of the recommended tests ( $17 \%$ in $2014,61 \%$ in 2016) and hepatitis B vaccine dose ordering ( $n=35$ in 2014, $n=110$ in 2016). However, the proportion of patients born in Africa or Asia tested for hepatitis B
\end{abstract}

Jacqueline A. Richmond

J.Richmond@latrobe.edu.au

1 The Royal Melbourne Hospital, Victorian Infectious Diseases Service, 300 Grattan Street, Parkville, Melbourne 3000, Australia

2 Viral Hepatitis Research Program, Australian Research Centre in Sex, Health \& Society, La Trobe University, 215 Franklin Street, Melbourne 3000, Australia

3 Department of General Practice, Faculty of Medicine, Dentistry and Health Sciences, The University of Melbourne, 300 Barry Street, Parkville, Melbourne 3000, Australia

4 Department of General Practice, Faculty of Medicine, Dentistry and Health Sciences, The University of Melbourne, 200 Berkely Street, Parkville, Melbourne 3000, Australia did not increase. Distribution of a patient held-reminder led to the greatest number of tests being ordered ( $n=54$ tests ordered in 1 month). Within a single primary care clinic situated in a high hepatitis B prevalence area, an intervention designed to improve adherence to hepatitis B testing guidelines, increased testing levels. A systematic approach can assist general practitioners to improve their understanding of hepatitis B testing and prioritise people most at risk.

Keywords Hepatitis B · Testing - Diagnosis · Primary health care $\cdot$ Quality improvement

\section{Introduction}

Globally, 400 million people have Chronic Hepatitis B (CHB) with the most significant burden experienced in Asia and Africa. The predominant routes of transmission are mother-to-child and sexual contact [1]. Best practice guidelines demonstrate that if CHB is diagnosed early, and managed and treated appropriately the risk of death related to hepatocellular carcinoma (HCC) and liver disease is significantly reduced [2-4]. In Australia, 239,167 people are estimated to have CHB, however, low diagnosis rates, low uptake of both specialist management and antiviral treatment and late diagnosis of hepatitis B related-HCC mean that hepatitis $\mathrm{B}$ is a cause of significant morbidity and mortality $[5,6]$.

A goal of $80 \%$ diagnosis rate by 2017 was set in the Australian National Hepatitis B Strategy 2014-2017 [7]. Although the Australian Hepatitis B Testing Policy [8] recommends hepatitis B testing for all people born in intermediate or high prevalence countries; Aboriginal or Torres Strait Islander people; children of women who have CHB; unvaccinated adults at high risk of infection; people with a 
family history of chronic liver disease or HCC or abnormal liver function tests or acute hepatitis; and family, sexual or household contacts of a person with or suspected to have hepatitis B, current estimates indicate that only $38 \%$ of people with hepatitis B have being diagnosed [5].

Given their focus on identification of risk factors, screening and vaccination programs and opportunity to support life-long monitoring, the role of general practitioners (GPs) in managing CHB has been explored as an alternative to specialist-led care [9]. However, numerous studies have shown that GPs' hepatitis B knowledge is poor, and many are unsure about who or how to test, or understand the link between CHB and HCC [10-12]. General practitioners' lack of understanding of hepatitis B also negatively affects patients' understanding of their infection and adherence to clinical management. Considering this, interventions focused on improving GP practice of hepatitis B testing, monitoring and management are needed to address the gap between best practice and the current sub-optimal management strategies.

Financial incentives, and audit and feedback on performance are two interventions commonly used to motivate GPs to undertake specific healthcare activities [13]. Other interventions designed to improve adherence to screening guidelines include linking screening to routine testing, capacity building activities including education, development of performance indicators and the use of prompts in electronic medical records (EMR) [14-16]. Such clinical interventions are most successful when they are shown to be effective, capable of being widely implemented and can be normalised into routine practice [17].

This case study explored the impact of four different interventions which sought to improve rates of hepatitis B testing in one primary care clinic over a 15 month period.

\section{Methods}

The study was conducted between September 2015 and December 2016. The primary care clinic is located in inner metropolitan Melbourne in the tenth highest prevalence area for hepatitis B in Australia [5]. The clinic employs 11 GPs and three nurses, and had a patient caseload of approximately 3000 in 2016.

A memorandum of understanding was developed between the study partners to outline the expectations and responsibilities of each party in relation to the provision of hepatitis B care and capacity building activities at the primary health care clinic. An Advisory Committee of stakeholders, comprising three clinic staff (GP, lead nurse and practice manager), an infectious diseases specialist physician, a tertiary hospital based viral hepatitis nurse and a community-based organisation representative, met quarterly during the project and advised on the design, implementation and evaluation of the interventions. Ethics approval was obtained from the La Trobe University Human Ethics Committee and the primary care clinic Human Ethics Advisory Group. Access to patients' EMR for the purpose of conducting quality assurance activities was also specifically addressed in the memorandum of understanding.

A group discussion was conducted with the clinic GPs and nurses in June 2015 during the design phase of the study, to focus the study aims and outcomes and to explore GP preferences for interventions. The discussion was framed around the Normalisation process theory [18], which states that for a complex intervention to be successfully normalised, four criteria must be met: all staff must agree that there is a problem to be addressed, and that the intervention will assist in addressing the problem. All staff must be aware of their role in the intervention, and agree on a way to deal with problems as they arise.

\section{Patient Population}

A baseline audit of the EMR was conducted in June 2015, using the 14 codes available for hepatitis B in the medical practice software to determine the number of patients with $\mathrm{CHB}$, at-risk of hepatitis $\mathrm{B}$, tested and vaccinated for hepatitis B. An active patient was defined as having attended the clinic since 1st January 2010; no age limits were applied to the source population.

\section{Interventions}

The project involved the implementation of four interventions during the study period: education, audit and feedback cycle, review of EMR and patient held reminder (Table 1).

\section{Outcome Measures}

Outcome measures were:

- The number of previously untested patients tested for hepatitis B.

- The number of patients who were correctly tested for HBsAg, anti-HBc, and anti-HBs.

- The proportion of patients from priority populations (born in Asia or Africa and people who identify as Aboriginal or Torres Strait Islander) tested for hepatitis B.

- The number of hepatitis B vaccine doses administered. 


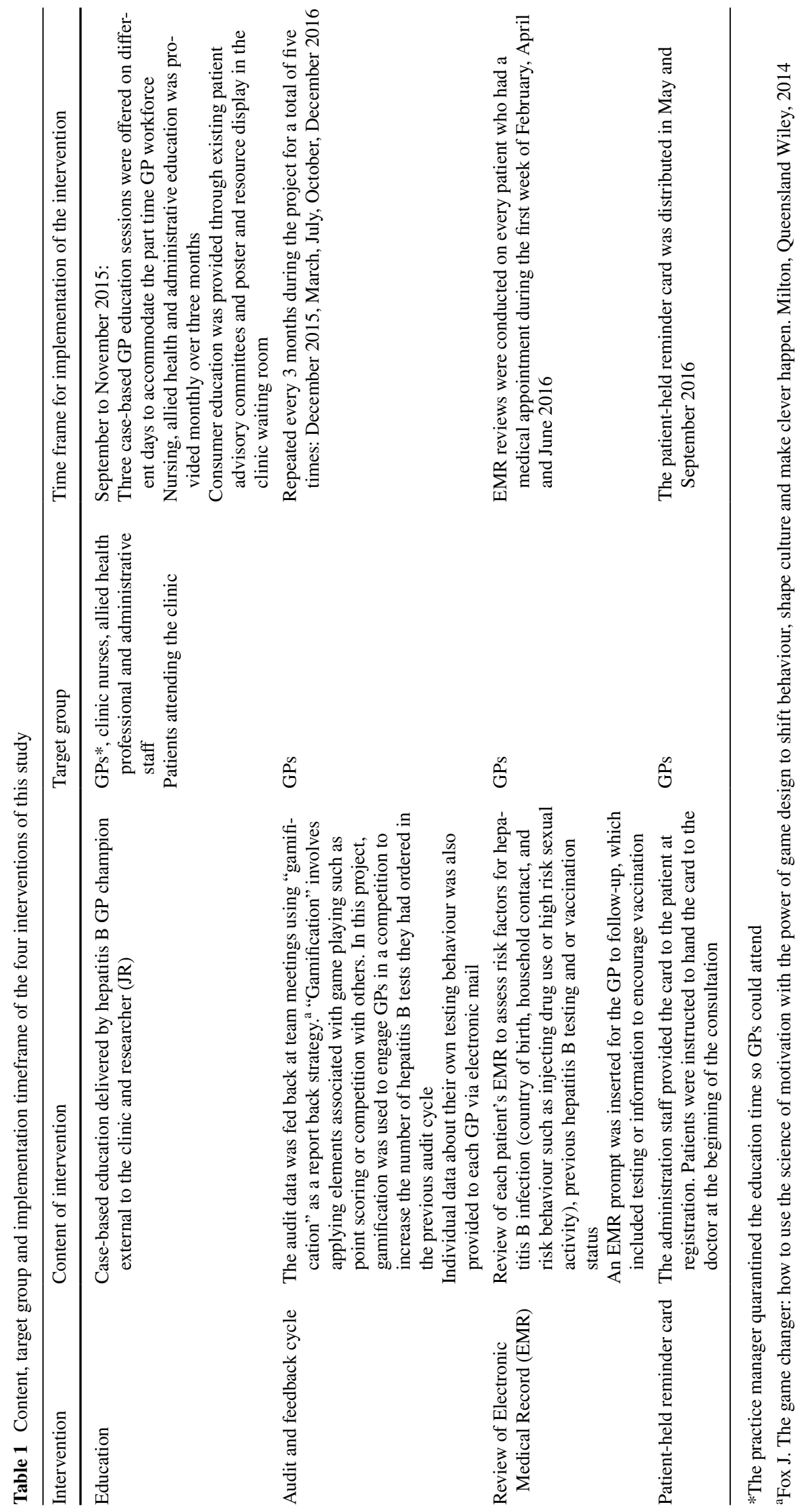




\section{Data Analysis}

The number of patients tested for hepatitis B was provided in an Excel spreadsheet on a quarterly basis by the onsite pathology provider. This data set was further developed during the audit and feedback cycle of the project. The EMR of each patient tested for hepatitis B during 2014, 2015 and 2016 was reviewed by the researcher +/- a clinic staff member, and consensus was reached on an assessment of their case definition and subsequent management. Data frequencies were calculated using pivot tables in the Excel spreadsheet.

\section{Clinic Characteristics}

In 2016, 11 GPs were employed at the clinic, ten were female, and the majority were employed part time (Table 2). The majority of patients attending the clinic were born in Australia (54\%), 29.3\% were born in intermediate hepatitis $\mathrm{B}$ prevalence countries and the remaining born in high hepatitis B prevalence countries including Greece (4.5\%), Italy (3.5\%), Vietnam (3.5\%), Somalia (2.7\%) and Ethiopia (2.5\%).

\section{Results}

The following section describes the impact of the four interventions on the hepatitis B testing practices of the clinic GPs.

At the beginning of the project in 2014, an estimate of the number of patients with CHB attending the clinic was calculated based on the hepatitis B prevalence of the patients' country of birth [19]. By this method it was estimated there were 100 patients with $\mathrm{CHB}$ attending the clinic. However, the initial audit of the EMR identified only 13 patients with CHB, suggesting a significant shortfall in diagnosis.

The group discussion conducted during the design phase involved four GPs and three clinic nurses, and revealed a low level of knowledge and confidence in $\mathrm{CHB}$ testing and management. A request for small group

Table 2 Effective full time equivalence for the general practitioners working in the clinic in 2016

\begin{tabular}{lll}
\hline Effective full time (EFT) & Hours per week (h) & $\begin{array}{l}\text { Number of } \\
\text { general practi- } \\
\text { tioners }\end{array}$ \\
\hline $0.1-0.3$ & $6-13$ & 6 \\
0.5 & 20 & 1 \\
0.71 & 27 & 2 \\
1.0 & 38 & 2 \\
\hline
\end{tabular}

education led to the first intervention. Nine of $15 \mathrm{GPs}$ attended one education session; four GPs attended all three sessions. Six GPs did not attend any of the education sessions as they did not work at the clinic on the days the education sessions were offered. The researcher provided tailored education to three of the six GPs during individual consultations. The remaining three GPs only worked on Saturdays and were not interested in receiving education.

\section{Hepatitis B Testing Practices}

Overall there was an increase in the number of tests ordered between 2014 and 2016. The average number of tests ordered by GPs per month increased from 15 in 2014 to 24 in 2016. The testing practices of each GP is presented in Graph 1. Of the 26 GPs who worked at the clinic between 2014 and 2016, only five (Drs A to E) were employed over the triennium. Doctors $\mathrm{B}, \mathrm{F}$ and $\mathrm{K}$ ordered the highest number of hepatitis B tests in 2016; each attended the three educational sessions offered during Intervention one and participated in the medical meetings when the audit data was presented.

Table 3 outlines the type and timing of interventions and the corresponding number of tests ordered. The highest number of tests were ordered in May 2016 during Intervention four.

In order to gain a comprehensive understanding of patients' hepatitis B status and susceptibility to infection the Australian Hepatitis B Testing Policy [8] recommends that hepatitis B testing should include three tests: HBsAg, anti-HBs and anti-HBc. Table 4 outlines the GP testing patterns between 2014 and 2016. The proportion of times the three tests were correctly ordered increased substantially between 2014 (17\%) and 2016 (61\%). This activity was a focus of Interventions one, two and three.

\section{Hepatitis B Testing According to Country of Birth}

While the overall number of patients tested for hepatitis B increased between 2014 and 2016, the proportion of patients born in Africa and Asia did not increase (Table 5). There was no difference between 2014, 2015 and 2016 in the proportion of people tested according to country of birth with most patients tested for hepatitis B in 2016 being born in Australia.

The country of birth of all patients attending the clinic in 2016 is listed in Table 6, along with the breakdown of individual countries in the highest hepatitis B prevalent regions. Patients born in Ethiopia and Somalia were more likely to be tested for hepatitis B than patients born in other high prevalence countries. This finding may be an artefact 


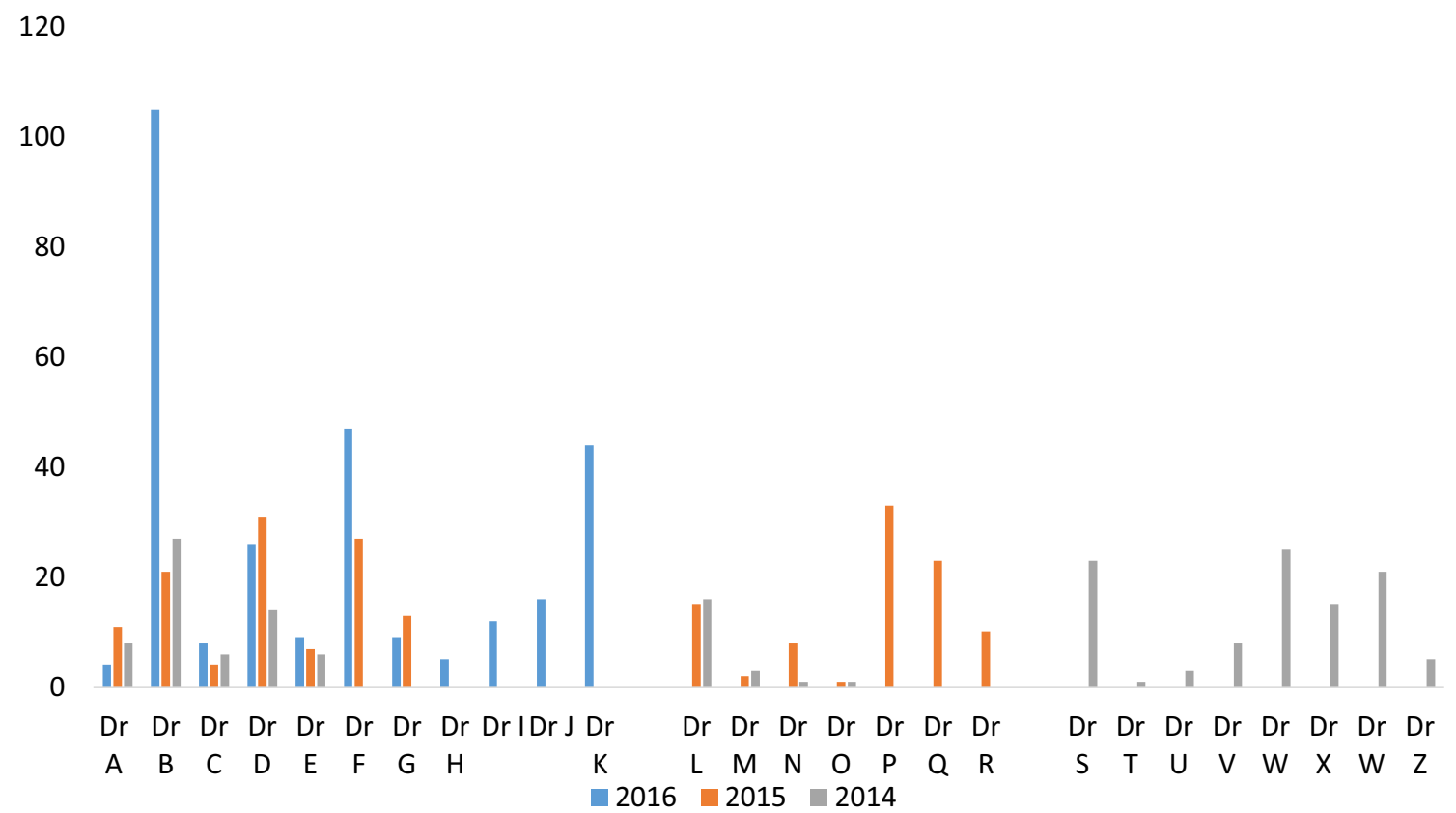

Graph 1 Hepatitis B tests ordered by individual general practitioners in 2014, 2015 and 2016

Table 3 Number of hepatitis $\mathrm{B}$ tests ordered by intervention and month

\begin{tabular}{|c|c|c|}
\hline Month and year & Intervention & $\begin{array}{l}\text { Total number of } \\
\text { tests ordered per } \\
\text { month }\end{array}$ \\
\hline Sept-15 & Education & 34 \\
\hline Oct- 15 & Education & 30 \\
\hline Nov-15 & Education & 17 \\
\hline Dec-15 & Audit and Feedback & 14 \\
\hline Jan-16 & No activity & 10 \\
\hline Feb-16 & $\begin{array}{l}\text { Electronic medical record } \\
\text { (EMR) review and } \\
\text { prompt }\end{array}$ & 18 \\
\hline Mar-16 & Audit and feedback & 25 \\
\hline Apr-16 & EMR review and prompt & 22 \\
\hline May-16 & Patient held reminder & 54 \\
\hline Jun-16 & EMR review and prompt & 27 \\
\hline Jul-16 & Audit and feedback & 20 \\
\hline Aug-16 & No activity & 20 \\
\hline Sep-16 & Patient held reminder & 22 \\
\hline Oct-16 & Audit and feedback & 30 \\
\hline Nov-16 & No activity & 22 \\
\hline Dec-16 & Audit and Feedback & 15 \\
\hline \multicolumn{2}{|c|}{$\begin{array}{l}\text { Total number of hepatitis B tests ordered during the intervention period (September } \\
2015 \text { to December 2016) }\end{array}$} & 380 \\
\hline
\end{tabular}

of antenatal screening which includes hepatitis B testing. Of the 28 women tested during antenatal screening, 11 (39\%) were born in Africa.

\section{Hepatitis B Test Results and Management}

The case definitions for the hepatitis B test results are provided in Table 7 . The hepatitis $B$ test results indicate the number of patients presenting to the clinic and susceptible 
Table 4 Testing patterns of the general practitioners in 2014 , 2015 and 2016

Table 5 Comparison of demographic characteristics of patients tested for hepatitis B in 2014, 2015 and 2016
Table 6 Country of birth for patients attending the clinic in 2016 and proportion of patients tested for hepatitis B by country of birth

\begin{tabular}{llll}
\hline $\begin{array}{l}\text { Year and number of patients } \\
\text { tested for hepatitis B }\end{array}$ & $\begin{array}{l}\text { Three hepatitis B tests ordered } \\
\text { (HBsAg, anti-HBc, anti-HBs) }\end{array}$ & Two tests ordered & One test ordered \\
\hline $2014(\mathrm{n}=183)$ & $17 \%(31)$ & $72 \%(132)$ & $11 \%(20)$ \\
$2015(\mathrm{n}=206)$ & $40 \%(82)$ & $56 \%(115)$ & $4 \%(9)$ \\
$2016(\mathrm{n}=285)$ & $61 \%(174)$ & $34 \%(96)$ & $5 \%(15)$ \\
\hline
\end{tabular}

\begin{tabular}{llll}
\hline Year the hepatitis B test was ordered & 2014 & 2015 & 2016 \\
Number of hepatitis B tests ordered & 183 & 206 & 285 \\
Mean age of patients tested & 34 years & 41 years & 43 years \\
$\%$ females & $67 \%(123)$ & $63 \%(130)$ & $56 \%(161)$ \\
$\begin{array}{l}\text { Number of antenatal hepatitis B tests ordered } \\
\% \text { Continent of birth }\end{array}$ & $11 \%(21)$ & $9 \%(18)$ & $10 \%(28)$ \\
Africa & & & \\
Asia & $20 \%(37)$ & $22 \%(45)$ & $19 \%(55)$ \\
Australia and Oceania & $6 \%(11)$ & $9 \%(18)$ & $12 \%(34)$ \\
Aboriginal and Torres Strait Islander & $37 \%(67)$ & $47 \%(96)$ & $44 \%(125)$ \\
Europe & $5 \%(9)$ & $1 \%(3)$ & $2 \%(7)$ \\
North America & $8 \%(15)$ & $8 \%(17)$ & $13 \%(36)$ \\
South America & $(0)$ & $0.5 \%(1)$ & $1 \%(2)$ \\
Missing data & $(0)$ & $0.5 \%(1)$ & $0(0)$ \\
\hline
\end{tabular}

${ }^{a}$ http://www.countries-ofthe-world.com

\begin{tabular}{lll}
\hline $\begin{array}{l}\text { Country of birth for patients } \\
\text { attending the clinic* }(\mathrm{n}=2994)\end{array}$ & $\begin{array}{l}\% \text { (n) of patients attending the } \\
\text { clinic according to country of } \\
\text { birth }\end{array}$ & $\begin{array}{l}\% \text { (n) of patients tested for hepatitis B } \\
\text { in 2016 according to country of birth }\end{array}$ \\
\hline Australia & $54 \%(1613)$ & $42 \%(120)$ \\
China & $3.2 \%(95)$ & $1 \%(2)$ \\
Egypt & $1.2 \%(37)$ & $0.5 \%(1)$ \\
England & $2.2 \%(66)$ & $2 \%(5)$ \\
Eritrea & $1.2 \%(35)$ & $2 \%(7)$ \\
Ethiopia & $2.5 \%(75)$ & $8 \%(24)$ \\
Greece & $4.6 \%(137)$ & $5 \%(15)$ \\
Italy & $3.6 \%(107)$ & $1 \%(3)$ \\
Malaysia & $1.0 \%(30)$ & $0.5 \%(1)$ \\
New Zealand & $1.5 \%(46)$ & $1 \%(2)$ \\
Somalia & $2.7 \%(81)$ & $5 \%(13)$ \\
Sudan & $1.4 \%(43)$ & $3 \%(8)$ \\
Turkey & $1.1 \%(33)$ & $1 \%(4)$ \\
Viet Nam & $3.3 \%(100)$ & $5 \%(14)$ \\
Missing/not stated & $3.3 \%(99)$ & $9 \%(26)$
\end{tabular}

* Only countries of birth with $>1 \%$ of the total population of patients attending the clinic in 2016 are included; therefore total proportion does not equal $100 \%$ to hepatitis B infection increased between $2014(\mathrm{n}=12)$ and $2016(n=96)($ Graph 2). This may be related to the increase in correct ordering of the three tests and subsequent ability to comprehensively assess patients' immunity and susceptibility. Six HBsAg positive patients were identified in 2016, however three had previously been diagnosed and were retested during antenatal screening.

Subsequent management of patients tested for hepatitis B was inconsistent (Graph 3). In 2016, 124 patients were tested and no further action was required because they had 


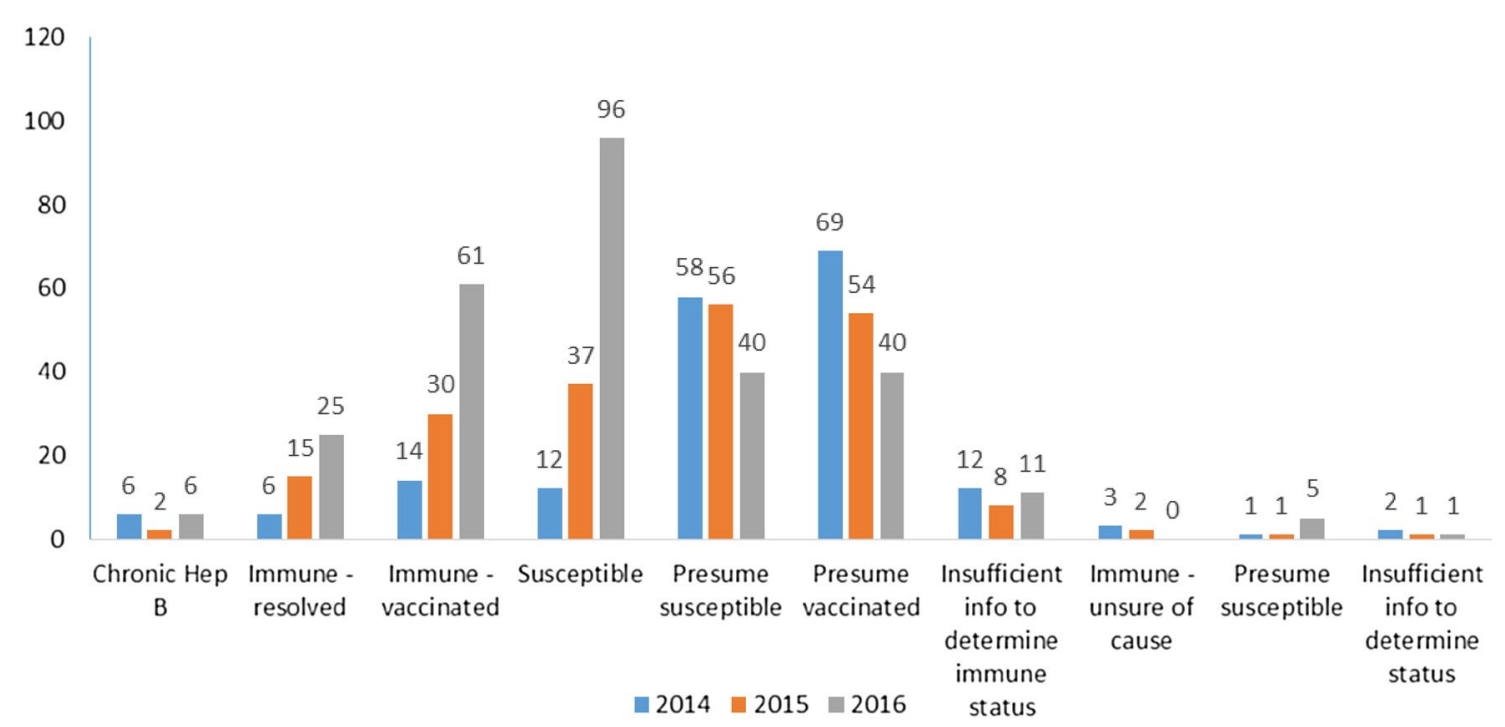

Graph 2 Results of hepatitis B tests in 2014, 2015 and 2016

Table 7 Case definitions for hepatitis B test results

\begin{tabular}{|c|c|}
\hline Case definition & Pathology results \\
\hline Chronic hepatitis B & $\begin{array}{l}\text { HBsAg detected and/or HBV viral } \\
\text { load detected }\end{array}$ \\
\hline Immune-resolved & $\begin{array}{l}\text { Anti-HBs detected } \\
\text { Anti-HBc detected }\end{array}$ \\
\hline Immune-vaccination & $\begin{array}{l}\text { Anti-HBs detected } \\
\text { (HBsAg and anti-HBc not detected) }\end{array}$ \\
\hline Susceptible & $\begin{array}{l}\text { HBsAg not detected } \\
\text { Anti-HBs not detected } \\
\text { Anti-HBc not detected }\end{array}$ \\
\hline CHB negative, presume susceptible to infection & $\begin{array}{l}\text { HBsAg not detected } \\
\text { Anti-HBs not detected } \\
\text { Anti-HBc unknown }\end{array}$ \\
\hline CHB negative, presume vaccinated & $\begin{array}{l}\text { HBsAg not detected } \\
\text { Anti-HBs detected } \\
\text { Anti-HBc unknown }\end{array}$ \\
\hline CHB negative, insufficient information to determine immune status & $\begin{array}{l}\text { HBsAg not detected } \\
\text { Anti-HBs unknown } \\
\text { Anti-HBc unknown }\end{array}$ \\
\hline Immune-vaccine-derived immunity or Natural immunity & $\begin{array}{l}\text { Anti-HBs detected } \\
\text { HBsAg unknown } \\
\text { Anti-HBc unknown }\end{array}$ \\
\hline Presume susceptible to infection & $\begin{array}{l}\text { Anti-HBs not detected } \\
\text { HBsAg unknown } \\
\text { Anti-HBc unknown }\end{array}$ \\
\hline Insufficient information to determine status & $\begin{array}{l}\text { Anti-HBc detected or not detected } \\
\text { Anti-HBs unknown } \\
\text { HBsAg unknown }\end{array}$ \\
\hline
\end{tabular}

either been vaccinated or had resolved infection. One hundred and three patients required follow up including further hepatitis B tests (where only one or two tests had been ordered) or vaccination because they were susceptible, but no further action was documented in the patient's EMR.
The number of patients with incomplete vaccination status (only one or two of the three doses administered) increased over the 3 years from six in 2014 to 18 in 2016.

The number of hepatitis $B$ vaccine doses ordered between 2015 and 2016 increased. In 2016, 110 doses were 


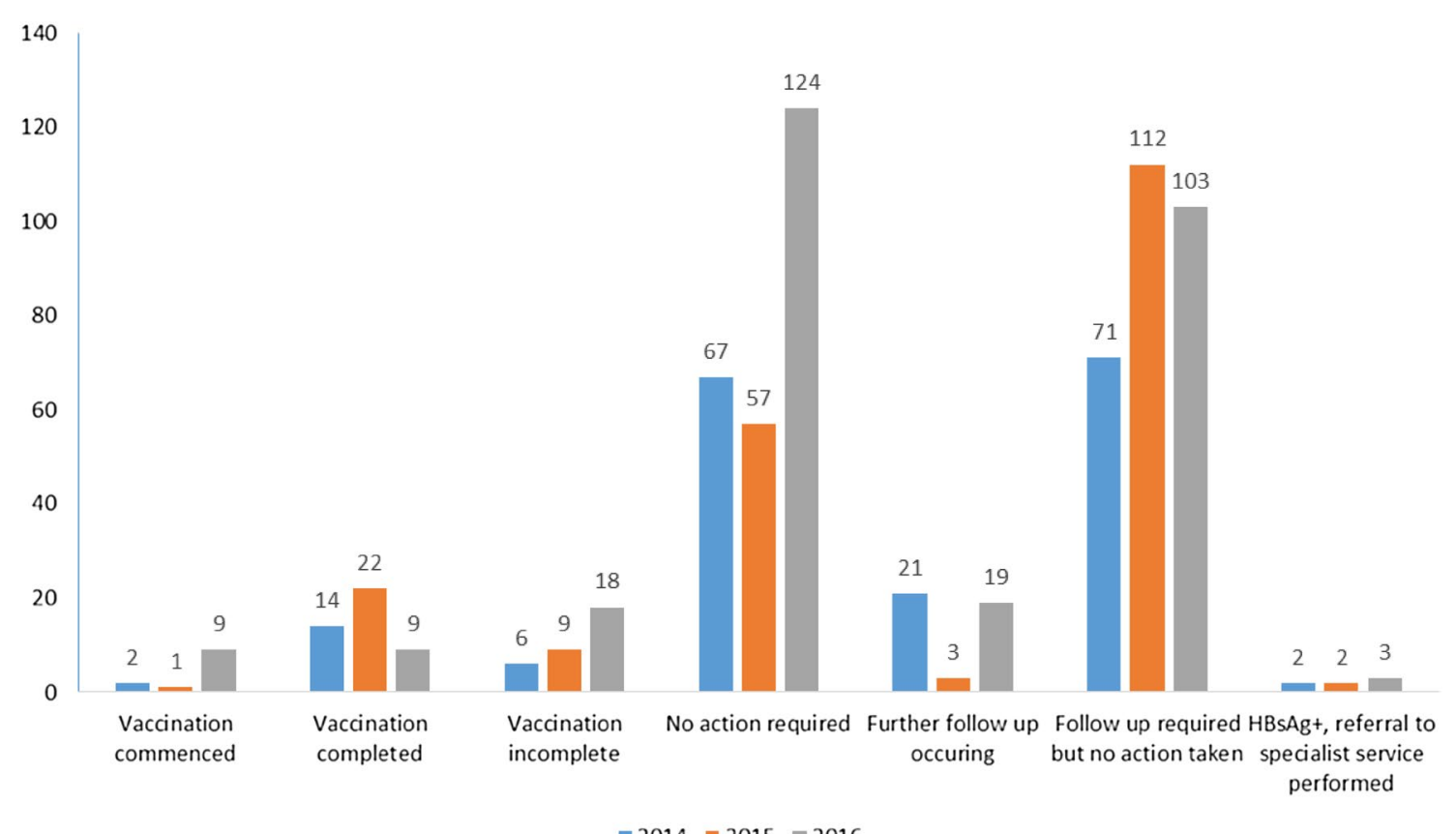

Graph 3 Medical management strategy provided after hepatitis B testing 2014, 2015 and 2016

ordered compared to 35 in 2014. Tracking the number of vaccine doses administered was difficult because of incomplete documentation in the EMR.

\section{Discussion}

Australia is considered a low hepatitis B prevalence country, however its cultural diversity means there are localised areas of intermediate to high prevalence. Given the projected high hepatitis B prevalence of the case study site and cultural diversity of its residents, the low number of patients identified with $\mathrm{CHB}$ attending the clinic was an unexpected finding. Based on the available data it was assumed there was an evidence-practice gap related to implementation of the Australian Hepatitis B Testing Policy. However, even with increased testing the number of patients identified with $\mathrm{CHB}$ did not increase. The case study results suggests that local epidemiological modelling may not be translatable to this primary care setting.

General practice can be a very unstable environment with GPs and patients moving in and out of the system. In this one clinic, only four GPs worked regularly between 2014 and 2016 and it was a predominantly part time workforce. Compared to 2014, the number of tests ordered in 2016 increased, however, the increase does not appear to have been sustained as reflected in a reduction to preintervention levels during periods of no activity. It is difficult to determine whether the knowledge that their testing practices were being monitored (Hawthorne effect) [20] led to a modification in their testing behaviour. While it is difficult to identify the impact of individual interventions on testing behaviour, because they ran concurrently, several positive practices were identified including the correct ordering of the serology tests (HBsAg, anti-HBc, and anti-HBs) and an increase in hepatitis B vaccine ordering. Correctly ordering hepatitis B tests reduces the barriers of repeat blood tests and allows for an immediate and comprehensive assessment of the patient's status, including need for vaccination; an outcome which also increased in this case study.

Improvements in testing behaviour were not translated to the provision of follow up care. In 2016, 96 patients (34\%) were identified as susceptible to hepatitis B infection; neither vaccinated nor infected. However, the proportion of patients who did not receive follow up care remained high (37\%) in 2016. Inadequate follow up was also identified in the context of immunisation. Of the 18 patients who had not completed the three dose immunisation in 2016, 15 had received two of the three doses. While it is challenging to encourage patients to return for a third dose (6 months later), it is an example of a missed opportunity for the nursing staff to use electronic reminders in the practice software.

General practitioners are accustomed to testing women for hepatitis B during antenatal screening. The proportion of women screened during antenatal care remained consistent over the 3 years, with many identified as being 
susceptible to infection, but follow up vaccination was only initiated in two cases post-partum. It is possible that interventions implemented during the project were focused on testing and did not provide GPs with enough support and guidance on follow up care. Another possible explanation is the widespread screening strategy adopted by several GPs within the clinic, meant that hepatitis B tests were added to existing pathology requests, with no established plan to follow up the results.

Country or continent of birth, primarily Africa and Asian countries, were promoted as the primary risk factor to trigger testing. Unfortunately the proportion of patients born in Africa and Asia tested for hepatitis B did not change between 2014 and 2016. This may be explained by variability in the testing behaviour of individual GPs. Several GPs expressed discomfort in 'racially profiling' their patients, instead preferring to test all patients, which led to the popularity of Intervention four (patient held reminder), which had the greatest impact on tests ordered. Anecdotal reports indicated the reminder card allowed the patient to initiate a conversation about hepatitis B testing, instead of the GP. It is possible one of the barriers to testing may have been that GPs lacked a 'script' for introducing hepatitis B into the patient consultation which has been reported in other clinical areas [21]. Patient-initiated testing, as occurred during intervention four, allowed GPs to prioritise testing from the complex range of health issues most patients attended with.

Interventions that aim to increase GP performance need to be combined with patient education strategies. While information was displayed in the clinic waiting room, it was difficult to evaluate the impact. Several large-scale initiatives in the United States of America, Asia Pacific, and Europe demonstrated the feasibility of community-based interventions in effectively screening large numbers of people with CHB [22]. However, limited resources mean this is not always possible. Anecdotally in this case study, the perceived stigma associated with hepatitis B among patients from Asia and Africa [23] created barriers to patient engagement. However, the most successful intervention involved patients requesting a test through the patient-held reminder.

There are several limitations to this single-site, case study related to the complexity of the concurrent implementation of the interventions; it is impossible to confidently identify which intervention had the greatest impact. A significant learning from this case study is the need to engage GPs at the outset of any interventional project to confirm that the topic and methodology is clinically and contextually appropriate. The GPs in this clinic were not consulted about their interest in participating in this project prior to its commencement, as the memorandum of understanding was negotiated with the clinic management. While the researcher attempted to include the GPs in the design phase, the GPs should have been consulted about their clinical priorities before the proposal was accepted. Lack of interest and priority as well as GP fatigue regarding hepatitis B were noted during the project. Of interest, higher rates of testing did not increase the identification of patients with CHB. Hepatitis B was not a priority health condition for these GPs because they were caring for very few patients with CHB.

In Australia, there is an attempt to shift the care of patients with CHB from tertiary to primary care [7]. Initiating hepatitis B testing in primary care is critical to reducing the morbidity and mortality of undiagnosed infection. It is clear from this case study this will only be achieved if GPs are engaged and prioritise hepatitis B as an issue in their patient cohort which leads to the adoption of hepatitis $\mathrm{B}$ testing as a standardised clinical practice. Normalisation process theory states that changing GP behaviour requires a shared understanding and commitment by all staff to achieve the intended outcomes. Consultation with primary care practitioners about their clinical priorities must be the first stage in identifying evidence-practice gaps. Increases in hepatitis B testing are unlikely to occur in general practice without a coordinated and systematic approach.

Acknowledgements The authors wish to acknowledge the general practitioners, nurses and administrators at the community clinic, in particular members of members of the advisory committee and Dr Mark Rose (St Vincent's Pathology) for their dedication and support of this project. Dr Jacqui Richmond received a Translation of Research into Practice Fellowship (2015-2016) from the National Health and Medical Research Council.

\section{Compliance with Ethical Standards}

Conflict of interest The authors do not have any conflict of interest to declare.

Open Access This article is distributed under the terms of the Creative Commons Attribution 4.0 International License (http:// creativecommons.org/licenses/by/4.0/), which permits unrestricted use, distribution, and reproduction in any medium, provided you give appropriate credit to the original author(s) and the source, provide a link to the Creative Commons license, and indicate if changes were made.

\section{References}

1. Ott, J. J., Stevens, G. A., Groeger, J., \& Wiersma, S. T. (2012). Global epidemiology of hepatitis B virus infection: new estimates of age-specific HBsAg seroprevalence and endemicity. Vaccine, 30(12), 2212-2219.

2. Sung, J. J. Y., Tsoi, K. K., Wong, V. W., Li, K. C., \& Chan, H. L. (2008). Meta-analysis: treatment of hepatitis B infection reduces risk of hepatocellular carcinoma. Alimentary Pharmacology and Therapeutics, 28, 1067-1077. 
3. European Association for the Study of the Liver (EASL) (2012). EASL Clinical Practice Guidelines: Management of chronic hepatitis B virus infection. Journal of Hepatology, 57(1), 167-185.

4. Lok, A.S.F., \& McMahon, B.J. (2009) American Association for the Study of Liver Diseases (AASLD) Practice Guidelines: Chronic hepatitis B: Update 2009. Hepatology, 50(3), 661-662.

5. Australasian Society for HIV, Viral Hepatitis and Sexual Health Medicine (ASHM) and Victorian Infectious Diseases Reference Laboratory, The Doherty Institute. (2016). Hepatitis B Mapping Project: Estimates of chronic hepatitis B prevalence, diagnosis, monitoring and treatment by Primary Health Network, 2014/15-National Report. ASHM and Melbourne Health 2016. Accessed 16 DeC 2016. http://www.ashm.org.au/HBV/ more-about/hepatitis-b-mapping-project.

6. Amin, J., Law, M. G., Bartlett, M., Kaldor, J. M., \& Dore, G. J. (2006). Causes of death after diagnosis of hepatitis B or hepatitis C infection: A large community-based linkage study. Lancet, 368(9539), 938-945.

7. Australian Government, Department of Health and Ageing (2014). Second National hepatitis B strategy 2014-2017. Canberra: Commonwealth of Australia. Accessed 19 Nov 2016. http://www.health.gov.au/internet/main/publishing.nsf/content/ ohp-bbvs-hepb.

8. Department of Health and Ageing, Department of Health and Ageing (2012). National Hepatitis B Testing Policy v1.2. Canberra: Commonwealth of Australia. Accessed 18 Nov 2016. http://testingportal.ashm.org.au/hbv.

9. Wallace, J., Hajarizadeh, B., Richmond, J., McNally, S., \& Pitts, M. (2012). Managing chronic hepatitis B: The role of the GP. Australian Family Physician, 41(11), 893-898.

10. Wallace, J., Hajarizadeh, B., Richmond, J., \& McNally, S. (2013). Challenges in managing patients in Australia with chronic hepatitis B: The general practitioners' perspective. Australian and New Zealand journal of public health, 37(5), 405-410.

11. Guirgis, M., Yan, K., Bu, Y. M., \& Zekry, A. (2012). A study into general practitioners' knowledge and management of viral hepatitis in the migrant population. Internal medicine journal, 42(5), 497-504.

12. Wallace, J., McNally, S., Richmond, J., Hajarizadeh, B., \& Pitts, M. (2011). Managing chronic hepatitis B: A qualitative study exploring the perspectives of people living with chronic hepatitis B in Australia. BMC Research Notes, 4(45), 1-7.

13. Hocking, J.S., Temple-Smith, M., van Driel, M., et al. (2016). Can preventive care activities in general practice be sustained when financial incentives and external audit plus feedback are removed? ACCEPt-able: A cluster randomised controlled trial protocol. Implement Science, 11(1), 122.

14. Guy, R. J., Ali, H., Liu, B., et al. (2011). Efficacy of interventions to increase the uptake of chlamydia screening in primary care: a systematic review. BMC Infectious Diseases, 11, 211.

15. Vedio, A., Liu, E. Z., Lee, A. C., \& Salway, S. (2017). Improving access to health care for chronic hepatitis B among migrant Chinese populations: A systematic mixed methods review of barriers and enablers. Journal of Viral Hepatitis, 1-15.

16. van Gemert, C., Wang, J., Simmons, J., et al. (2016). Improving the identification of priority populations to increase hepatitis $\mathrm{B}$ testing rates, 2012. BMC Public Health, 16, 95.

17. Murray, E., Treweek, S., Pope, C., et al. (2010). Normalisation process theory: a framework for developing, evaluating and implementing complex interventions. BMC Medicine, 8, 63.

18. May, C., Finch, T., Mair, F., et al. (2007). Understanding the implementation of complex interventions in health are: the normalization process model. Health Services Research, 7, 148.

19. Schweitzer, A., Horn, J., Mikolajczyk, R. T., Krause, G., \& Ott, J. J. (2015). Estimations of worldwide prevalence of chronic hepatitis B virus infection: a systematic review of data published between 1965 and 2013. Lancet, 386(10003), 1546-1555.

20. McCarney, R., Warner, J., Iliffe, S., van Haselen, R., Griffin, M., \& Fisher, P. (2007). The Hawthorne Effect: a randomised, controlled trial. BMC Medical Research Methodology, 7, 30.

21. Ricketts, E. J., O'Connell Francischetto, E., Wallace, L. M., Hogan, A., \& McNulty, C. A. M. (2016). Tools to overcome potential barriers to chlamydia screening in general practice: Qualitative evaluation of the implementation of a complex intervention. BMC Family Practice, 17, 33.

22. Robotin, M.C., \& George, J. (2014). Community-based hepatitis B screening: what works? Hepatology International, 8(4), 478-492.

23. Wallace, J., McNally, S., \& Richmond, J. (2007). National Hepatitis B Needs Assessment. Melbourne: Australian Research Centre in Sex, Health and Society, Latrobe University. 